\title{
Childhood Grade I Meningioma
}

National Cancer Institute

\section{Source}

National Cancer Institute. Childhood Grade I Meningioma. NCI Thesaurus. Code C71300.

A grade I meningioma that occurs during childhood. 